\title{
Rat Pars Intermedia Carcinoma
}

National Cancer Institute

\section{Source}

National Cancer Institute. Rat Pars Intermedia Carcinoma. NCI Thesaurus. Code C92183.

A malignant epithelial neoplasm arising from the pars intermedia of the anterior pituitary gland. 